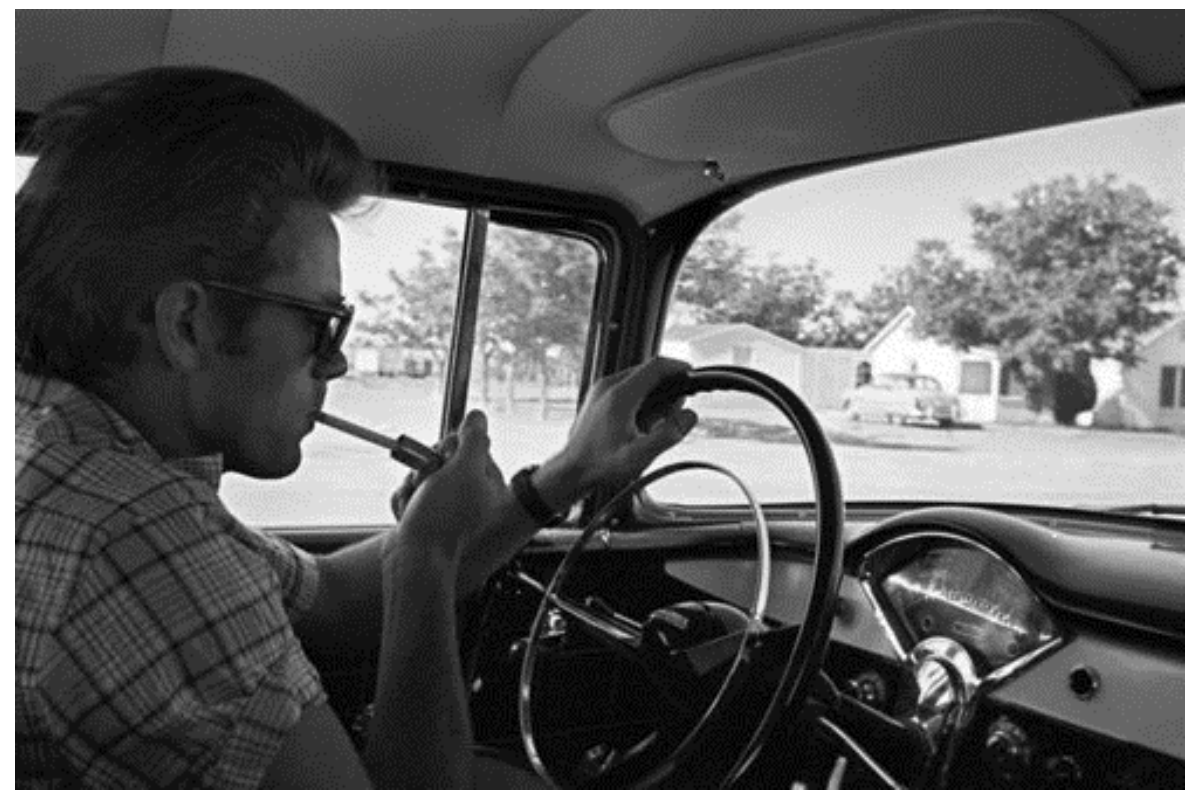

\title{
Espaços urbanos como arenas de (trans)formações identitárias na literatura contemporânea
}

Urban spaces as arenas of identity (trans)formations in contemporary literature

Ricardo Sobreira*

\section{Resumo:}

O objetivo do artigo é demonstrar, por meio da análise do conto "Coalinga 1/2 Way", do autor americano Sam Shepard (2002), como a metrópole pós-moderna (SOJA, 1989, 1995; DAVIS, 1992; WIDMER, 1998) constitui um lócus de (trans) formação e deformação da identidade. A partir de uma revisão de teorias sobre formação de subjetividades (HALL, 1987, 1992; RINCÓN, 1995; BAUMAN, 2004), empreendemos uma análise do artefato literário em vinculação com o espaço urbano da cidade de Los Angeles, Califórnia.

Palavras-chave: Cidade; Identidade; Los Angeles; Sujeito Pós-moderno; Sam Shepard.

\section{Abstract:}

This article aims at showing how the postmodern metropolis (SOJA, 1989, 1995; DAVIS, 1992; WIDMER, 1998) constitutes an area of identity (trans)formation and deformation in the story "Coalinga 1/2 Way" by American author Sam Shepard (2002). Through a revision of theories on formation of subjectivities (HALL, 1987, 1992; RINCÓN, 1995; BAUMAN, 2004), the literary narrative is analyzed in association with the urban space of Los Angeles, California.

Keywords: City; Identity; Los Angeles; Postmodern Subject; Sam Shepard.

\footnotetext{
* Docente adjunto do Mestrado Profissional Interdisciplinar em Ciências Humanas e do curso de Letras (Português/Inglês) da UFVJM, campus de Diamantina-MG.
} 
A relação entre o ser humano e o espaço urbano passa necessariamente pelo reconhecimento de que a interação de ambos engendra subjetividades. Nesse sentido, pode-se presumir que a construção identitária do sujeito seja feita a partir de bases territoriais (cf. VÉRAS, 2004, p.119).

Partindo dessa premissa, nosso trabalho empreende uma leitura dos sentidos que se constituem e que circulam nos espaços, sobretudo os urbanos, plasmados artisticamente pela narração literária contemporânea. Por essa razão, elegemos como objeto de estudo o conto ficcional "Coalinga 1/2 Way" (2002), ${ }^{1}$ do escritor Sam Shepard. Esse autor norte-americano tem se destacado pela associação de uma densa carga emocional a grandes centros urbanos como a cidade de Los Angeles, Califórnia.

Buscando compreender analítica e teoricamente o espaço urbano da metrópole americana como arena de (trans)formações e deformações identitárias pelo viés da recriação literária de um reconhecido artista contemporâneo, optamos por dividir o presente trabalho em quatro partes, a saber: na primeira seção, revisitamos alguns estudos especializados (HALL, 1987, 1992; RINCÓN, 1995; BAUMAN, 2004) e, a partir disso, procedemos a uma delimitação teórica de três concepções distintas de subjetividade/identidade (sujeito do Iluminismo, sujeito sociológico e sujeito pósmoderno) com as quais operamos a fim de evitar equívocos de ordem terminológica. A segunda seção, intitulada "Representações literárias de construtos identitários", será dedicada a uma breve apresentação do escritor em pauta e de suas produções artísticas com o objetivo de demonstrar como Shepard, em sua vasta produção, tem representado o referido espaço urbano como um cenário de fragmentações de identidades e de perdas subjetivas profundas. Na terceira seção, encontra-se a análise propriamente dita do conto "Coalinga 1/2 Way", na qual retomamos as três concepções teóricas de sujeito e de identidade discutidas na primeira parte com o intuito de mostrar como a cidade de Los Angeles (CA) é representada como um mesocosmo que contribui decisivamente para o descentramento da subjetividade humana e para a fragmentação de sua identidade. A última seção destina-se à breve retomada de aspectos estudados ao longo do percurso de análise e às considerações finais.

\footnotetext{
${ }^{1}$ Esse conto foi publicado em português brasileiro sob o título de "Coalinga - metade do caminho" (SHEPARD, 2003). Nossa análise baseia-se, entretanto, na versão original em inglês.
} 


\title{
1. Concepções de identidade
}

Questões relacionadas à identidade têm sido motivo de intensa reflexão em diferentes campos do conhecimento, sobretudo, no período histórico atual, no qual observamos ocorrerem profundas transformações históricas, fenômenos sociais complexos, a progressiva internacionalização das grandes metrópoles, a sofisticação tecnológica e uma nova configuração do capitalismo no ocidente, chamado por Ernest Mandel de "capitalismo tardio" (cf. JAMESON, 2006, p.22-23). Essas intensas transformações representam um momento crucial dentro de um longo processo de perda de poder e influência de instituições responsáveis pela mediação dos valores sociais (cf. LYOTARD, 1993, p.40).

(i) Há mais ou menos três séculos, acreditava-se que instituições, como família nuclear, Estado e Igreja, garantiam a unidade e a coerência das sociedades (BAUMAN, 2004, p.23). Os sujeitos formados nesse contexto emergiam como seres unificados, cujo cerne era, por um lado, a razão, e por outro, a fé na existência de uma alma imortal, responsável por uma posição de sujeito - isto é, uma identidade - contínua e centrada. O exemplo abaixo, retirado de Shakespeare, ilustra a noção de profunda coerência interna do eu (self) de Romeu, expresso na fala de Julieta:

\author{
JULIETA: Oh, não jures pela lua, a inconstante lua \\ Que sofre alterações mensais em seu globo circular, \\ Para que teu amor não se mostre do mesmo modo variável. \\ ROMEU: Pelo que jurarei então? \\ JULIETA: Não jures em absoluto; \\ Ou, se quiseres, jura pelo teu gracioso $e u$ [self], \\ Que é o deus da minha idolatria, \\ E em ti eu crerei (2006, p.174, grifo nosso). ${ }^{2}$
}

Por meio do diálogo inscrito na tragédia elisabetana, observamos que a personagem opõe claramente a mutabilidade da lua à extrema fixidez intrínseca atribuída ao sujeito ficcional (Romeu), que, ao ser também associado à figura de deus, sugere autossuficiência, centralidade e onipotência.

Stuart Hall (1992) define esse tipo de indivíduo como o "sujeito do Iluminismo", pois ele é dotado de capacidades de raciocínio, consciência e ação (p.276). Embora a peça de Shakespeare anteceda a emergência do chamado Século das Luzes, identificamos na passagem uma possível figuração do tipo de sujeito plenamente

\footnotetext{
${ }^{2}$ Salvo quando indicado na bibliografia, todas as traduções livres utilizadas no presente trabalho são de responsabilidade do autor da pesquisa.
} 
estabilizado, que mais tarde seria teorizado pelos filósofos iluministas. Os subsídios teóricos de Hall, por exemplo, provêm de posições filosóficas como as de Locke. Segundo o iluminista inglês, o que define a identidade do sujeito humano é sua consciência reflexiva, isto é, o conjunto das faculdades responsáveis por relacionar ações, percepções e experiências passadas e presentes em um todo consistente. No Ensaio acerca do Entendimento Humano (1690), Locke expõe essas ideias da seguinte maneira:

\begin{abstract}
Uma vez que a consciência sempre acompanha o pensamento; e, por meio disso, distingue-se [o sujeito humano] de todos os outros entes pensantes, nisto apenas consiste a identidade pessoal, isto é, a uniformidade de um ser racional: e tanto quanto esta consciência pode ser estendida de maneira retroativa a qualquer ação de pensamento passada, tanto alcança a identidade da pessoa; trata-se da mesma personalidade agora tal como era então (1959, p.449, grifo nosso).
\end{abstract}

Em síntese, esse sujeito projetado pelas ideias iluministas, também chamado de "sujeito monádico", caracteriza-se como um núcleo uniforme e autossuficiente cuja formação se dá antes pela conformidade dos processos mentais dentro da consciência (vista aqui como entidade reificada) do que pela interação - isto é, consciência como processo - com elementos da realidade exterior. Conforme sintetiza Docherty (1993), esse sujeito do Iluminismo estaria "reduzido à participação ou confirmação de seus próprios processos racionais em vez de comprometer-se em participar da alteridade material de um mundo objetivo" (p.8).

(ii) O relativo declínio dessas instituições, fato que marca a modernidade e que se reflete na própria dinâmica dos espaços urbanos, dá origem a indícios de ruptura na própria trama de algumas sociedades. Surge entre os indivíduos uma tendência a examinar e a reformular os valores e comportamentos recorrentes do passado associados a essas instituições tradicionais em face do apelo livre de outras forças concorrentes e discursos competitivos forjados na conjuntura socioeconômica moderna.

Nesse contexto de grande complexidade, Hall distingue o desenvolvimento da noção de um novo sujeito moderno, o chamado "sujeito sociológico", constituído a partir da consciência de que o núcleo interno do sujeito não é mais autônomo, como ocorria no sujeito do Iluminismo ou cartesiano, mas é formado em relação a outros sujeitos significativos, responsáveis por mediar os valores, símbolos e sentidos ao sujeito sociológico (HALL, 1992, p.276). Esse processo se daria como se "quem eu sou — o 'verdadeiro' eu — fosse formado em relação a todo um conjunto de outras narrativas" (HALL, 1987, p.44). Por essa razão, a identidade é (trans)formada a partir 
de atos de interação entre o eu, ainda em posse de um núcleo uniforme (o "verdadeiro" eu), e a sociedade, que fornece significados e valores culturais aos quais o sujeito tenta se alinhar. A identidade, dessa forma, é a sutura do sujeito na estrutura sociocultural, que, até o alto modernismo, ainda pode ser definida como unificada e previsível (HALL, 1992, p.276). Essa noção de previsibilidade do local que o sujeito deve ocupar nos espaços civilizados emana, segundo Bauman (2004), da noção de que durante a maior parte da modernidade, a ideia das classes sociais, por exemplo, era muito mais forte e, dessa forma, a posição de sujeito era determinada por uma trajetória inequívoca. Nesse sentido, Bauman observa que "no âmbito dessa rede de familiaridade, do berço ao caixão, o lugar de cada pessoa era evidente demais para ser ponderado, muito menos negociado" (p.18). Devido a essa consciência de pertencimento a uma classe, o sujeito sentia-se confortável o bastante para perceber-se como parte de um corpo coletivo e para desenvolver o que o teórico chama de tripla confiança: em si mesmo, nos outros e na sociedade (BAUMAN, 2004, p.48-50).

(iii) No entanto, as atuais configurações do capitalismo tardio aliadas ao fenômeno da pós-modernidade, ${ }^{3}$ com seus enormes avanços em termos de mobilidade urbana, tecnologia e comunicação, têm abalado as antigas formas de identidade e, por essa razão, fornecido uma arena propícia para o surgimento não de uma identidade centrada, unificada e coerente, mas de identidades fragmentárias, instáveis e em permanente construção (HALL, 1992). Como atesta Bauman, a "fragilidade e a condição eternamente provisória da identidade não podem mais ser ocultadas" (2004, p.16).

Nesse mesmo sentido, Rincón (1995), com base em aspectos socioculturais do capitalismo tardio, propõe a seguinte distinção entre formulações clássicas de sujeito e o sujeito pós-moderno:

\footnotetext{
${ }^{3} \mathrm{O}$ termo pós-modernidade é usado para marcar a transição entre o paradigma da modernidade e um novo paradigma (cf. SANTOS, 2000, p.34; VATTIMO, 2007, p.ix), conhecido também como era pós-moderna. Dessa forma, a pós-modernidade refere-se a um estágio social, histórico e econômico, que supostamente sucede a modernidade. Essa transição seria marcada pela emergência do capitalismo tardio - ou do "capitalismo desorganizado", conforme defende Santos (2000, p.87) - e pela decorrente substituição da produção de mercadorias através do trabalho industrial por estilos de vida individualistas, sobretudo nas chamadas sociedades urbanas mais avançadas, baseadas no consumismo exacerbado de produtos e símbolos, em grande parte, oferecidos pela cultura e mídia de massa (SMITH, 2001, p.215; TRODD, 2001; AUSLANDER, 2004). Nessa passagem para a economia do capital multinacional - marcada pelas tecnologias midiáticas high tech e pelo extravasamento de fronteiras geopolíticas do capital e da cadeia produtiva - alguns críticos defendem que o sujeito humano sofre um processo de fragmentação do antigo ideal de uma identidade pessoal unificada e autossuficiente (JAMESON, 1986, p.67; HALL, 1992; SANTOS, 2000, p. 107).
} 
O sujeito reflexivo, centrado e unitário das Kritiken de Kant e das abstrações de Max Weber teria sido substituído [na pós-modernidade] por um cambiante sujeito descentrado, difuso e fragmentário, que se move em um espaço que já não está socialmente estruturado de uma maneira binária. Com isso, a questão da constituição de identidades também foi reformulada (p.111, grifo nosso).

Por essa razão, o caráter frágil e temporário das identidades humanas é em geral percebido como a chamada crise de identidade, cuja precipitação se deve à derrocada da soberania e influência dos chamados "monopólios de interpretação" (SANTOS, 2000, p.89), representados pelas instituições mediadoras (e suas narrativas mestras) que tinham como papel principal fornecer referenciais sólidos para o processo de individuação dos sujeitos. Lyotard, como sabemos, associa esse declínio das instituições a uma crise geral de legitimação das narrativas mestras. Segundo o pensador, a recente "incredulidade em relação aos metarrelatos" constitui um sintoma da possibilidade sem precedentes de se "questionar a validade das instituições que regem o vínculo social" (1988, p.xvi).

Hall distingue, nesse contexto, a produção de um "sujeito pós-moderno", concebido como desprovido de uma identidade fixa, essencial ou permanente (1992, p.277). Isto é, um sujeito encarado como ponto de convergência e divergência simultânea de identidades contraditórias, que o impulsionam em diferentes sentidos, forçando-o a intercambiar posições de sujeito como se fossem peças do vestuário. Nesse sentido, Bauman sugere que o mais sensato na pós-modernidade (ou "modernidade liquida", como o autor prefere definir a dominante cultural contemporânea) seria a possibilidade de "vestir" identidades como "uma capa leve pronta a ser tirada a qualquer momento" (2004, p.30).

Trocas de identidade, fragmentações da personalidade e sujeitos instáveis, que vagam sem rumo por metrópoles pós-modernas, são alguns dos temas que têm dado a tônica do universo ficcional de Sam Shepard desde o início de sua produção artística. No que segue, discutimos brevemente como essas questões são plasmadas literariamente pelo autor norte americano.

\section{Representações literárias de construtos identitários}

Autor de uma produção dramática e de uma ficção em prosa orientada em favor de instabilidades lógicas, alinearidades temporais e experimentalismos formais (cf. ROUDANÉ, 2002), Sam Shepard tende a explorar criticamente em suas peças e contos os aspectos míticos da cultura americana, bem como as contradições entre passado 
histórico e presente, entre o real e o ilusório e entre as condições materiais e a dimensão espiritual da existência humana (GRAY, 2011, p.320-322). Suas personagens, sejam dramáticas ou não, tendem a emergir não como sujeitos integrais, compostos por uma lógica de caracterização e de motivação, mas como seres ficcionais fragmentários, construídos a partir de colagens de identidades, temporalidades e emoções, como improvisações de jazz (SHEPARD, 2006, p.61-62).

$\mathrm{O}$ autor tem realizado a maior parte de suas atividades criativas nos palcos, para os quais já escreveu, montou e publicou mais de quarenta e cinco peças, dentre elas Angel City (1976), True West (1980), Fool For Love (1983), A Lie of the Mind (1985), Simpatico (1994) e Buried Child (1978), vencedora do Prêmio Pulitzer de Melhor Drama. Por seu trabalho no teatro, Shepard tem se consolidado como um dos principais expoentes do drama americano da segunda metade do século XX (cf. SIEGEL, 1982, p.236; COHN, 1988, p.1118-1119; SHEWEY, 1997, p.4; ZELLAR, 2002, p.1; JAMES, 2002, p.30; GRAY, 2011, p.319-322).

Em sua extensa carreira no cinema, cabe mencionar seus roteiros para os filmes Paris, Texas (França, Alemanha, EUA, 1984) - dirigido por Wim Wenders e premiado com a Palma de Ouro no Festival de Cannes - e Estrela Solitária (Don't Come Knocking, EUA, Alemanha, 2005) - também dirigido por Wenders e protagonizado pelo próprio Shepard.

Paralelamente às carreiras de dramaturgo, roteirista, ator e diretor, Shepard, a partir dos anos setenta, tem se dedicado à publicação, ao menos uma vez a cada década, de uma coletânea de textos diversos, predominantemente em prosa. Esses trabalhos incluem as coletâneas Hawk Moon (1973), Motel Chronicles (1982), Cruising Paradise (1996), Great Dream of Heaven (2002) e Day Out of Days (2010). Com exceção de Great Dream of Heaven e Cruising Paradise, que são coletâneas de contos, os demais livros, além de contos, incluem também relatos, crônicas, poemas e monólogos.

Essas narrativas literárias, em especial as coligidas em Great Dream of Heaven, tematizam sensações de nostalgia e de ansiedade em decorrência dos processos descontrolados de urbanização sofridos pelo velho oeste americano, um território selvagem conhecido por seus cânions e desertos, mas que foi "tragado" pela progressiva fúria empreendedorística das incorporadoras imobiliárias. $\mathrm{O}$ progresso e a suburbanização do espaço ocasionaram a substituição das paisagens naturais por autoestradas, motéis, redes de restaurantes especializados em fast-food, cassinos e condomínios. Esse avanço da chamada América pós-moderna contribuiu para tornar 
obsoletos os estilos de vida das famílias rurais dessa região com uma rapidez vertiginosa (DeROSE, 1992, p.94). Dessa forma, o conto de Shepard mobiliza uma série de imagens que sugerem a perda de contato da figura romântica do homem natural com a natureza selvagem e a transformação deste sujeito em um eu deslocado, em crise com sua identidade e carente de referências sólidas de localização e de identificação.

A perda de elos consistentes com a terra no sentido histórico tradicional também motiva, em vários textos de Great Dream of Heaven, a desagregação dos vínculos sociais e familiares, levando sucessivas gerações, sobretudo individuos do sexo masculino, a desenvolverem comportamentos antissociais e a buscarem total isolamento.

Observadas as devidas proporções, podemos afirmar que as complexidades do sujeito humano e a possibilidade deste, com relativa frequência, trocar de identidades tem sido uma preocupação de Sam Shepard desde seus primeiros textos (McGHEE, 1993, p.169-170; SHEWEY, 1997, p.45). A peça True West trata das rivalidades entre dois irmãos que, a certa altura, trocam de identidades, profissões e vícios. Esse intercâmbio de posições de sujeito resulta em crises de identidade e frustrações, que os levam afinal a tentar assumir a identidade do pai ausente.

Situação semelhante acomete várias personagens da peça Simpatico: o fracassado Vincent "Vinnie" T. Webb "rouba" a identidade de seu ex-sócio e comparsa Lyle Carter com a finalidade de vender fotografias comprometedoras a Darrel P. Simms, um terceiro envolvido em suas trapaças do passado. Ao visitá-lo, Vinnie encontra esse obscuro sujeito já em posse de um novo nome (Ryan Ames) e empresa, em torno da qual forjou uma identidade completamente nova. Durante o confronto final de Vinnie com Simms (que finge ser Ames), este último indaga: "Quantas vidas o senhor acha que um homem pode viver, Sr. Webb? Quantas vidas dentro desta mesma vida?” (SHEPARD, 1996, p.61, grifo nosso). A julgar por esses e outros textos do autor, as identidades (ou diferentes "vidas" dentro de uma única vida) são, portanto, temporárias, flexíveis e tendem a acompanhar a extrema mutabilidade e volatilidade dos sujeitos ficcionais, conforme veremos na análise de um conto do livro Great Dream of Heaven.

No que segue, examinamos manifestações estilizadas dessas três concepções de subjetividade (sujeito do Iluminismo, sujeito sociológico e sujeito pós-moderno) no conto "Coalinga 1/2 Way". A proposta de análise baseia-se no método adotado por Aronowitz (1995), que "monitora" o impacto exercido por diferentes perspectivas 
identitárias sobre as posições de sujeito de um trabalhador portorriquenho fictício durante momentos distintos da história americana (p.115-116). No caso do conto “Coalinga 1/2 Way", essas três perspectivas de identidade enformam o progressivo declínio emocional de um pai de família (family man) americano comum.

Em virtude de se tratar de uma representação artística estilizada da forma como diferentes construtos instanciam-se ficcionalmente no texto literário, devemos colocar toda a questão temporal entre parênteses. Como sabemos, seria impossível que um único indivíduo da realidade empírica vivesse durante séculos para experienciar três das grandes alterações no paradigma social e histórico da identidade nos termos de Hall (1987, 1992). Na literatura, entretanto, tais "saltos" espaçotemporais são não apenas possíveis, mas também frequentes, sobretudo no universo imaginário de Shepard. Os contos e peças do autor americano caracterizam-se pela instalação e pela subversão de preceitos convencionais do realismo tradicional (cf. DEMASTES, 1987) e até mesmo pela incorporação de elementos da literatura fantástica (cf. McGHEE, 1993). Conforme já mencionamos, não podemos ler as referências espaço-temporais dos textos de Shepard apenas em sentido literal como se fossem dados empíricos, mas devemos também extrapolar esses referenciais uma vez que o espaço na obra do escritor possui um caráter emocional mítico e o tempo abarca a dimensão simbólica da jornada humana. Esse tratamento particular de aspectos temporais e espaciais permitem até a coexistência, muitas vezes na mesma cena ou na mesma passagem narrativa, de "versões" discrepantes de uma mesma personagem. Esperamos que essa abordagem contribua não para "congelar" temporalmente os espaços, mas para dar ao leitor uma visão da simultaneidade com que Shepard concebe as experiências das personagens vinculadas a lócus dramáticos onde incidem ao mesmo tempo diferentes temporalidades históricas.

\section{Multiplicação/Dissolução de identidades em Shepard}

“Coalinga 1/2 Way" (SHEPARD, 2002, p.11-18) é o segundo conto do livro Great Dream of Heaven. O texto - uma provável reelaboração de um microconto publicado em Motel Chronicles (1982, p.121) — narra a breve viagem do protagonista, que vai possivelmente da região de San Francisco, Oakland ou Sacramento, no estado da Califórnia, até Los Angeles. O interesse da história nessa jornada em particular devese ao fato de que o homem, cujo nome não é referido no texto, está deixando sua esposa 
e filho para juntar-se a uma outra mulher, também casada. Tendo em vista o fato de que o protagonista faz uma pausa na cidade mencionada no título do conto com a finalidade de telefonar para a mulher e só então avisá-la de que a está deixando, percebemos que a ideia de abandoná-la partiu de uma decisão irrefletida e, conforme ele descobrirá mais tarde, precipitada. O local escolhido por ele para contatar a esposa é saturado de imagens disfóricas que prenunciam o cenário urbano: uma cabine telefônica à beira do acostamento poluído, ladeada por um enorme campo de confinamento de gado de onde se avista todo o vale San Joaquin sob o sol escaldante.

O diálogo com a esposa tem um tom seco, quase trágico, pois o protagonista não tem respostas quando ela indaga-lhe os motivos do fim de um casamento de mais de quinze anos. Como é típico das figuras masculinas em Shepard, essa personagem parece incapaz de articular sentimentos e emoções em sua fala, que é marcada por reticências e hesitações incômodas. A mulher pede-lhe que volte, mas ele lhe diz que já viajou demais para retornar. Ela então se propõe a viajar metade do caminho e, em um último esforço de reconciliação, pede-lhe que também retorne a outra metade. Dessa maneira, os dois poderiam se encontrar em algum ponto do caminho, provavelmente no município de Gilroy. Em termos metafóricos, adentrar o perímetro urbano de Gilroy representaria o fato de que ambos poderiam encontrar um meio-termo satisfatório e diminuir a distância — não apenas geográfica, mas também afetiva - existente entre eles. Contudo, dada a incompatibilidade irreconciliável dos elementos masculino e feminino no horizonte da poética de Shepard (cf. MURPHY, 2002, p.136), o homem recusa-se a tentar encontrar-se com a mulher no meio do caminho.

Após uma breve discussão sobre qual dos pais deve comunicar a separação ao filho do casal, o homem encerra o diálogo com a antiga companheira, que lhe faz a ominosa pergunta: "para onde eu devo ir?". Ele então retoma a viagem e chega a Los Angeles à noite. Durante o percurso até o hotel o protagonista é "bombardeado" por estranhas imagens da cosmópole pós-moderna: astros e estrelas do cinema em cenas de explosão ou simulações de orgasmos em painéis e outdoors espalhados pelo trajeto; limusines com vidros escuros; adolescentes com piercings sendo revistadas na entrada das boates; pessoas sozinhas e drogadas. O homem hospeda-se no hotel Tropicana "sem bagagem, nem escova de dentes, nem uma troca de roupa de baixo" (p.17). O quarto tem cheiro ruim e oferece apenas uma cama e um telefone, que ele usa para entrar em contato com a outra mulher, com quem manteve uma relação pouco explicada durante dois anos. Na verdade, o texto não esclarece se o protagonista teve algum outro contato 
— incluindo o visual — com essa mulher a não ser por telefone. Ela fica surpresa com a decisão do protagonista e recusa-se a ir até o hotel encontrá-lo, pois está a ponto de embarcar para Indiana, no extremo oposto do país, onde seu marido acaba de receber uma proposta de trabalho e está a sua espera. Desnorteado, o protagonista replica a indagação feita horas antes por sua esposa: "Para onde eu devo ir?” (p.18, grifo nosso).

Embora pontuada por um curso de eventos banais envolvendo personagens e situações superficiais, essa pequena narrativa, em um nível mais simbólico, constitui um comentário sobre o desfacelamento de uma visão tradicional e unitária do oeste americano por meio de um processo de degradação física e emocional da personagem que culmina na metrópole californiana. O protagonista anônimo do conto é um ser ficcional recorrente em trabalhos anteriores do autor como True West e Paris, Texas. Trata-se de um pai (old man) que não se identifica com a vida nem tampouco com os valores associados à vida em comunidade e, em especial, à família como vínculo social; e, sem aviso, decide romper com esses laços, tornando-se "patologicamente independente" (HALL, 2002, p.247). No caso do protagonista de "Coalinga 1/2 Way", o motivo alegado por ele para a ruptura é a união com uma outra mulher. Mas, em face da surpresa da outra pessoa e a aparente falta de relação entre os dois, percebemos que a partida tem menos que ver com a busca de uma nova relação do que com um desejo inconsciente de desfazer-se de compromissos e isolar-se. O texto deixa claro que o narrador já agiu dessa maneira antes e embora relute em seguir sua "sina", parece compelido a fazê-lo devido ao mesmo imperativo que levou seu próprio pai a também abandonar a família. O confinamento de gado próximo à cidade de Coalinga sugere aprisionamento e ausência de escolha e prefigura o impasse vivido pela personagem. Embora não desejasse cometer os erros do pai, sente-se fadado, devido a uma linhagem "hereditária" inelutável, a replicar os comportamentos do patriarca; afinal, não há volta, pois ele está agora "profundamente dentro do músculo de uma ação" alheia ao seu controle. A conversa com a esposa deixa claro os traumas causados por esse padrão masculino de fugas e de abandonos recorrentes no ânimo de ambos:

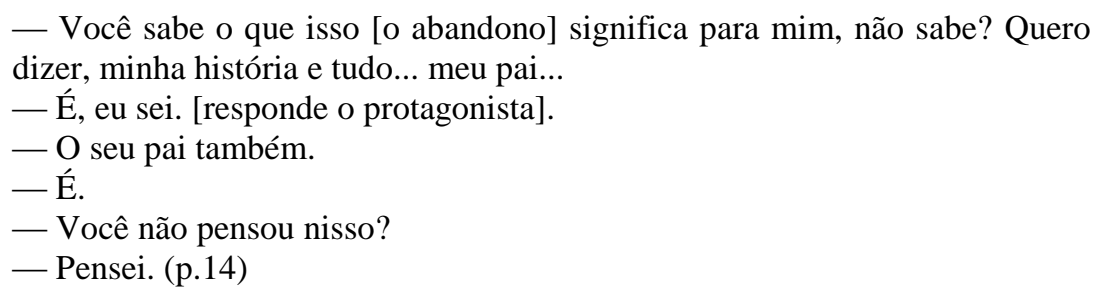


Conforme observa Wetzsteon (2006), os dilemas das personagens de Shepard são vivenciados em um espaço emocional (p.7) e, por essa razão, devemos entender cada etapa do deslocamento do protagonista pelas várias localidades como elemento simbólico que indicia o desfacelamento do sujeito centrado. O tema da viagem em geral revela muitos aspectos da vida dos seres ficcionais e pode evocar traços do destino humano em um sentido mais amplo, pois a jornada tem muitos significados não apenas em termos de contrastes entre cidades e paisagens, mas também no que diz respeito aos sentimentos e às transformações experimentadas pelo viajante. No território ficcional de Shepard, "o local em que [um indivíduo] cresce e vive molda de forma invisível a maneira como este pensa, percebe a realidade e relaciona-se com o ambiente" (DEROSE, 1992, p.58). Por essa razão, as personagens do autor tendem a encarar o deslocamento dessa rede de familiaridade como uma "fonte de grande perturbação pessoal", capaz de deixar a "psique [...], de uma maneira misteriosa, em desarranjo" (DEROSE, 1992, p.58). Dessa maneira, lemos o deslocamento do protagonista em ao menos dois sentidos: o afastamento do protagonista de um ambiente de familiaridade (local de residência) rumo a um outro de completo estranhamento (Los Angeles); e, em um nível mais simbólico, e, portanto, não literal, pois desapegado em relação a uma temporalidade rígida, a trajetória de deslocamento da ideia de sujeito centrado rumo a uma concepção pós-moderna de identidade. Nesse sentido, o motivo da viagem figura como metáfora do caráter necessariamente móvel da identidade. Silva (2005) explicita essa noção nos seguintes termos:

\footnotetext{
Embora menos traumático que a diáspora ou a migração forçada, a viagem obriga quem viaja a sentir-se 'estrangeiro', posicionando-o, ainda que temporariamente, como o 'outro'. A viagem proporciona a experiência do 'não sentir-se em casa' que, na perspectiva da teoria cultural contemporânea, caracteriza, na verdade, toda identidade cultural. Na viagem, podemos experimentar, ainda que de forma limitada, as [...] inseguranças [...] da instabilidade e da precariedade da identidade (p.88, grifo nosso).
}

Nos textos de Shepard, a condição pós-moderna, por meio de seus elementos artificiais e fragmentários situados sobretudo nas grandes cidades americanas, instaura uma conjuntura social e cultural extremamente desfavorável para o sujeito humano e para os ideais de autenticidade e de unidade do oeste americano cristalizados no imaginário nacional desde o final do século XIX. Dessa maneira, podemos afirmar que Shepard é um autor que pode ser associado ao pós-modernismo, porém, que, ao mesmo tempo, produz textos que, de maneira paradoxal, resistem e opõem-se à pósmodernidade. Suas peças e contos com frequência projetam sentimentos de insatisfação 
com as condições existentes na contemporaneidade e manifestam uma preferência por uma miragem de uma América mais "natural". O problema com essa mirada nostálgica, Shepard nos mostra, reside no fato de ela se constituir em uma espécie de desejo paradoxal por uma determinada imagem de nação, que provavelmente jamais existiu, a não ser em romances e filmes Western ou, conforme nota Görmez, em subgêneros televisivos como propagandas do cigarro Marlboro (2007, p.142).

Como assinala King (1988), algumas produções artísticas de Shepard são marcadas por fusões espúrias entre elementos contrastantes como, por exemplo, a coexistência simultânea de duas ou mais temporalidades distintas em uma mesma cena ou narrativa (p.ix). Esse também é o caso de textos em que convivem em um mesmo espaço-tempo duas "metades" ou duas ou mais "versões" da mesma personagem (DEMASTES, 1987, p.237-241). Embora de maneira menos experimental que peças como True West e Buried Child, podemos dizer que o deslocamento empreendido pelo protagonista de "Coalinga 1/2 Way", conforme veremos, abrange temporalidades distintas dentro do "mesmo" dia, bem como fragmenta a ideia de sujeito inteiro em função de uma justaposição de diferentes posições de sujeito fluidas da mesma personagem.

Desse modo, devemos ler a trajetória do protagonista de "Coalinga 1/2 Way" como uma alegoria do processo de fragmentação do sujeito centrado. Por essa razão, devemos pôr a questão da temporalidade do conto entre parênteses e, de maneira provisória, presumir que esse deslocamento também se dá ao longo de um processo histórico e cultural que perpassa toda a modernidade, chegando à concepção pósmoderna de sujeito.

Podemos distinguir no conto de Shepard três perspectivas distintas do mesmo sujeito, que coincidem não apenas com as três localidades por onde este transita, mas também com os três modelos de identitários de Hall (1992) discutidos na primeira seção. A análise a seguir tentará identificar essa tripla perspectiva a partir do estudo de aspectos dos três diferentes tempos e espaços que compõem a narrativa: i) um mês antes da separação, o protagonista encontra-se próximo do lar; ii) durante a fuga, em uma parada na região de Coalinga; iii) ao final da fuga, perambulando pelas ruas de Los Angeles.

(i) Inicialmente, o narrador nos remete, por meio de uma digressão, a um momento, que, embora narrado na metade do conto, antecede o início propriamente dito da narração. Nesse estágio, pressupomos que o sujeito ainda se perceba como um 
sujeito centrado ou monádico, comparável em tese ao antigo sujeito do Iluminismo (cf. HALL, 1992, p.276). Durante esse flashback, o narrador nos dá conta de que há menos de um mês antes de deixá-la, o protagonista teve uma "conversa imaginária" com a esposa na qual ele lhe dissera que nunca a deixaria e que jamais repetiria os erros de seu pai. Como sabemos, "a identidade é relacional”, isto é, ela é demarcada pela diferença (WOODWARD, 2005, p.9). Nesse sentido, portanto, o sujeito projetado pelo conto estabelece sua identidade a partir da marcação da diferença radical em relação ao outro (no caso, seu pai ausente) com o qual não se identifica. A figura do pai "traidor" é então percebida como uma alteridade perturbadora em relação aos discursos e valores que estruturam a rede de familiariadade responsáveis pela estabilização da identidade do protagonista.

Na ocasião dessa "conversa imaginária", ele sentia-se "cheio de convicção" e, ao contrário do pai, tinha "a impressão de si mesmo como um homem honesto" (p.16). Embora os atos posteriores revelem que de alguma forma ele já nutria, ao menos em nível inconsciente, um impulso de trocar a família por um futuro questionável, parece claro que naquele momento o sujeito ainda dispõe de referenciais consistentes de identificação. Além da família, um desses referentes diz respeito à sua comunhão com a natureza de sua localidade, representada pelo "vento quente do vale", que lhe fornece uma "fonte de força" (p.16). A possibilidade dessa perfeita identificação entre homem e mundo natural remete a um estágio pré-moderno, que será eclipsado nas fases posteriores do deslocamento do protagonista, quando este se confrontará finalmente com o pós-moderno. $\mathrm{O}$ uso de palavra com valor absoluto (never) para negar qualquer intenção de ruptura com os vínculos sociais dos quais faz parte demandam um grau de certeza e de continuidade que só pode emanar de um sujeito constante (que não prevê mudanças) e consciente ("cheio de convicção") da centralidade desses elementos para a formação de sua própria identidade.

Além disso, o fato de o sujeito ignorar as evidências do mundo exterior (os abandonos prévios cometidos por seu pai; a possível sensação de domesticidade sentida ao lado da esposa) e concentrar-se em construtos mentais ("conversa imaginária", promessas) gerados apenas em sua mente com o intuito de convencer a si mesmo, mostram um sujeito que se julga de certa forma autossuficiente e que não depende de outra realidade a não ser a projetada por sua dimensão psíquica. A convicção do protagonista, no entanto, não é imune às instabilidades e, conforme nota James (2002), nas histórias de Shepard, "famílias [...] desmoronam, os homens [...] veem tudo o que 
acreditam ser verdade virar de cabeça para baixo em um instante" (p.30). Isso mostra que, mesmo nesse lócus em que Shepard inicialmente "encena" uma versão do ser humano equiparável ao homem do Iluminismo, já há a incidência desagregadora da modernidade e, sobretudo, da pós-modernidade a solapar essa relação produtiva entre homem e natureza.

(ii) Em um segundo momento, que coincide com a parada em Coalinga no início da narrativa, o texto fornece uma visão alternativa do protagonista, que acaba de iniciar o processo de deslocamento de seu antigo núcleo de estabilidade para ir em busca de um novo centro de identificação. Embora essa nova relação acabe se mostrando disfuncional, o homem parece crer que ocupando uma outra posição de sujeito equiparável à do sujeito sociológico (cf. HALL, 1992, p.276), a interação com um círculo diferente de relações vá fornecer sentidos e valores que o ajudem a superar sua crise de identidade momentânea e a redescobrir o seu "verdadeiro" eu. O protagonista acredita que a nova relação com essa outra mulher vá completá-lo de alguma maneira e elege uma parte dela (a voz) como o elemento que tornará completa sua vida: "Ele já pegou o telefone em todos os estados emocionais possíveis, aguardando a voz do outro lado. A voz sem a qual - ele se convenceu — não pode mais viver. A voz pela qual ele desistiu de tudo" (SHEPARD, 2002, p.17). A esposa até mesmo o repreende por tentar resolver "essa coisa [...] dentro de você" (p.14, grifo nosso) com uma troca de mulheres. A mera busca por um outro sujeito significativo não é suficiente para estabilizar sua identidade.

Há alguns elementos que nos levam a ler o espaço ficcional de Coalinga como uma representação da modernidade. O primeiro deles está no fato de que as imagens de morte e devastação — "ossos de rato, latas de cerveja amassada e camisinhas desbotadas"; "absolutamente nada se move, tudo claro até o horizonte cinza esfumaçado" (p.11) - mobilizadas pelo narrador para descrever as adjacências do espaço urbano de Coalinga evocam o desconforto em relação à modernidade plasmado nos seguintes versos de The Waste Land (1922), de T. S. Eliot: "o rio não suporta garrafas vazias, restos de comida, / lenços de seda, caixas de papelão, pontas de cigarro / E outros testemunhos das noites de verão [...] / Um rato rasteja macio entre as ervas daninhas / Arrastando seu viscoso ventre sobre a margem” (2004, p.151).

Parte da desolação que vemos em "Coalinga 1/2 Way" deve-se à obliteração da natureza como efeito da ação humana, que coloniza a paisagem original com confinamentos de gado, detritos urbanos da América consumista, rodovias e telefones 
públicos. Desse modo, o conto associa o desconforto físico e emocional do protagonista, percebido por meio das imagens mobilizadas pelo texto, aos processos inerentes à modernização avançada.

O contraste entre a aridez naturalmente cinza do vale e o design funcional, tecnológico da cabine telefônica, por exemplo, incomoda de maneira profunda o protagonista: "o [...] modernismo [do telefone] enoja-o; faz com que ele se sinta ainda pior, mais distante" (p.11, grifo nosso). Nesse sentido, Coalinga emerge como um espaço emocional que representa as instabilidades e deslocamentos intrínsecos à modernidade. Nesse espaço emocional, o sujeito percebe que os discursos, valores e significados que estruturam sua comunidade de identificação estão perdendo a estabilidade. Essa perda é sugerida, no plano da ficção, pelas turbulências da família nuclear, pelo crescente desligamento da natureza, isto é, pelo seu próprio deslocamento físico e afetivo da antiga rede de familiaridade.

O texto projeta, nesse segundo momento, uma concepção sociológica de sujeito, pois, embora este se encontre imerso em ansiedades e perdas subjetivas complexas, ainda busca estabelecer uma interação com outro sujeito significativo e tem a percepção de si mesmo como um todo unificado. No tocante à narrativa, esse sentido é sugerido na passagem em que o protagonista "vê a si mesmo à distância nesse momento, como se estivesse olhando de uma grande altura, como da perspectiva de um falcão: um homem minúsculo em um espaço vasto, agarrando-se a um pedaço de plástico preto" (p.15). Essa mirada privilegiada (do alto, através da visão aguçada da ave de rapina) de si mesmo como um sujeito inteiro, "suturado" a uma estrutura maior, que, mesmo em crise, ainda é capaz de lhe oferecer segurança e firmeza, reforça a relativa unidade da condição moderna.

(iii) No entanto, ao aproximar-se do terceiro momento da narrativa, alguns desses aspectos são abalados não só pela consolidação do deslocamento do sujeito de sua rede de familiaridade, mas também pela entrada no território pós-moderno. Se The Waste Land em certa medida expressa o "horror" de Eliot em face da crescente obliteração de aspectos da natureza na cultura urbana moderna (GREGSON, 2004, p.118), a arte de Shepard, por sua vez, assume uma crescente preocupação com a perda total desses elementos pelo sujeito na pós-modernidade.

No caso de "Coalinga 1/2 Way", o local que concentra a cultura, os símbolos, valores e imagens pós-modernos é obviamente Los Angeles, ponto de chegada do protagonista. No domínio teórico recente, Los Angeles aparece em geral como a 
cosmópole pós-moderna por excelência ou, como define Edward Soja, o "mesocosmo da pós-modernidade" (1989, p.244; 1995, p.128). Widmer (1998) explica que isso se deve ao fato de que L.A. caracteriza-se por uma intrínseca "instabilidade geográfica" devido ao seu potencial para um apocalipse cinematográfico. Segundo o autor, a cidade está situada sobre uma falha geológica, o que faz com que a população sinta-se constantemente "ameaçada de aniquilação por forças da natureza como terremotos e o deserto [Mojave]". Tremores diários fazem com que a população lembre-se com frequência da ameaça do Big One, o grande epicentro que varreria definitivamente a cidade do mapa. A analogia com o pós-moderno deve-se ao fato de que a cidade em si evoca, além da ideia de instabilidade, uma imagem de "horizontalidade, [devido à] sua vastidão, sua falta de centro" (WIDMER, 1998, p.3). Por essa razão, Davis (1992) observa que Los Angeles tem sido progressivamente simbolizada como uma “"anticidade', [uma espécie de] Gobi dos subúrbios” (p.47).

No contexto específico da produção artística de Shepard, Los Angeles costuma figurar como um local repleto de evocações disfóricas, pois este território, que no passado era caracterizado pela natureza rústica, foi "engolido" pelos subúrbios, cuja paisagem circundante não é mais dominada por vales, mas por autoestradas e outdoors, servindo de abrigo à indústria de "ilusões" cinematográficas de Hollywood (CLUM, 2002, p.177). A ocorrência mais intensa dessa ideia encontra-se na peça Angel City (1976), em que Los Angeles é representada como um monstro que "está comendo [as pessoas] vivas" (SHEPARD, 2005, p.71). Essa ameaça de devoração possui tanto um sentido figurado - o risco de aniquilamento do indivíduo em virtude da exploração do artista pela indústria cinematográfica ou da corrupção moral da cidade - quanto um sentido literal: algumas das personagens têm a pele "carcomida" por algum tipo de radiação emitida pela metrópole e, ao final, algumas acabam se transformando literalmente em monstros esverdeados (SHEPARD, 2005, p.108). Mais tarde, em um microconto sem título, publicado na coletânea Motel Chronicles, Shepard volta a referir-se a Los Angeles como a "serpente enorme e enlouquecida": "Sua boca aberta repleta de presas, os olhos faiscantes, paralisada em um bote de pura paranoia" (1982, p.121).

A Los Angeles de "Coalinga 1/2 Way" é inanimada. Entretanto, não deixa de pulsar com seres ficcionais e imagens que fornecem um contraste em relação à antiga rede de familiaridade do protagonista. As ruas dessa cosmópole do cinema entretêm 
seus olhos com uma sucessão de simulacros, ${ }^{4}$ cujo referente no real se perdeu ou nunca existiu: imagens brilhantes de artistas, que fingem orgasmos ou esquivam-se de explosões geradas por efeitos de computação gráfica, impressas sobre a superfície sem profundidade dos outdoors; a fachada de neon da boate exibe uma cor processada artificialmente, sem correspondente na natureza; o logotipo em forma de palmeira do hotel Tropicana remete a uma imagem estereotipada de clima tropical, que é simulada por meio de uma estrutura de neon vermelha. A cidade emerge, portanto, saturada de imagens sugerindo sentidos de ilusão, artificialidade e alucinação. E "na grandeza do devaneio, o eu se perde depressa!" - a frase do pequeno poema em prosa de Baudelaire (2007, p.38), emprestada de contexto diverso, pode servir, aqui, de síntese da situação da personagem de "Coalinga 1/2 Way", bem como de prenúncio de seu destino.

A megalópole constitui um espaço social pós-moderno do qual, de acordo com Jameson, a natureza e suas antigas relações com a vida agrária não só desapareceram do campo de visão, mas foram eclipsadas da própria memória (2006, p.365). Por essa razão, a Los Angeles de "Coalinga 1/2 Way" converte-se em um espaço emocional notadamente desconfortável para o protagonista, que em meio a esse ambiente, assume as características de um sujeito deslocado. Esse deslocamento de um sistema consistente de representação cultural - seu território natural, sua comunidade e sua família nuclear - rumo a um campo de forças marcado por imagens inautênticas e discursos competitivos, levam-no a experimentar perdas subjetivas.

Esses prejuízos incluem a substituição do papel central no vínculo estável com a família pelo anonimato e isolamento de um quarto de hotel, que também projeta um ambiente impessoal e alienado; além da ruptura de sua conexão com a natureza representada pelo vento quente do vale que soprava em sua região, garantindo-lhe "uma fonte de força", e potencializava, de modo simbólico, sua ligação com a comunidade e com a identidade de "homem honesto" (p.16). Essa posição de sujeito entra em crise quando, no nível da ficção, a oposição entre sua identidade "central" ("homem honesto", marido e pai de família) e a radical alteridade de seu pai ("traidor", pai

\footnotetext{
${ }^{4}$ Termo utilizado aqui no sentido conferido por Baudrillard (1993), segundo o qual a sociedade pósmoderna realizou uma completa substituição das noções de realidade e sentido por símbolos e signos. Desse modo, restaria apenas a experiência do real como simulações. Os símbolos e signos aos quais o teórico alude referem-se aos produzidos pela cultura e pela mídia, que levariam as pessoas a confiarem mais nos simulacros do que na realidade, na qual essas mesmas simulações se baseariam. Ainda segundo o autor, o simulacro precede o original e a distinção entre realidade e representação é eclipsada uma vez que não há um saber legitimado capaz de "separar o verdadeiro do falso, o real de sua ressurreição artificial” (BAUDRILLARD, 1993, p.194-199).
} 
ausente) deixa de ser marcada. O sujeito sofre um deslocamento de sua identidade inicial ao identificar-se com um sistema de valores referentes a uma outra posição de sujeito, vista de maneira antagônica por ele.

A perda do aspecto acabado e fixo da identidade do protagonista é sugerida na passagem em que ele se aproxima da cosmópole pós-moderna: "Neste momento um certo garoto amedrontado toma o lugar do homem; empurra-o, agarra o volante, curvase para frente na escuridão, e desce a montanha serpenteante rumo às luzes selvagens de Los Angeles" (p.16). Dessa maneira, podemos dizer que o sujeito experimenta uma multiplicação de identidades: de "homem honesto", ele passa a identificar-se com o pai "traidor"; em seguida, como vimos na passagem reproduzida acima, essa identidade é substituída pela de um jovem ousado e irresponsável, que assume o volante (o controle) do sujeito. A desestabilização da noção prévia de identidade estável que o protagonista vivencia é acompanhada de medo, afinal ele sente-se como um garoto "amedrontado". Byers (1995) associa esse tipo de ansiedade do macho contemporâneo com um sentimento de "pomofobia", isto é, uma resposta desconfortável do sujeito a ameaças impostas pela pós-modernidade como "mudanças na base material e econômica", "o colapso geral das narrativas mestras", bem como o declínio da família nuclear como "o local privilegiado da segurança e do ser do sujeito" (p.5-6), entre outras. No tocante ao conto de Shepard, as sensações de medo e de aversão do protagonista em relação às complexidades instaladas pela pós-modernidade aumentam na mesma proporção em que o sujeito vivencia múltiplos deslocamentos de sua identidade, culminando com o abandono da outra mulher.

Ao telefonar para ela, o protagonista identifica-se dizendo "sou $e u$ " (p.17, grifo nosso), mas esse "eu" que fala tornou-se muito diferente do sujeito que prometera à esposa não abandoná-la. Neste momento, o sujeito "veste", nos termos de Bauman (2004, p.30), as identidades de "garoto amedrontado" e "amante".

A posição de sujeito referente ao "homem honesto" que "nunca [...] deixaria a esposa" ficou, de modo literal, para trás. O momento em que essa antiga identidade passa por um descentramento é marcado no conto pela passagem em que o protagonista termina o relacionamento com a esposa, isto é, rompe com a promessa, e deixa o telefone - a última conexão com a antiga "comunidade" — fora do gancho: "Ele tenta ficar observando o telefone pendendo através do espelho retrovisor, mas logo o perde de vista, como alguma pequena parte de si mesmo que foi deixada para trás” (p.15). Essa "pequena parte", que fica pendente, sem um ponto firme de apoio, sugere a identidade 
"abandonada" pelo protagonista após complexos processos de fragmentação e o deslocamento do sujeito de sua rede de familiaridade.

Analisando por esse ângulo, é possível argumentar que o conto de Shepard acompanha a fragmentação do ideal de sujeito centrado, que resulta em uma multiplicidade de identidades temporárias e instáveis que evocam as características do sujeito pós-moderno (cf. HALL, 1992, p.277). A pergunta — "Para onde eu devo ir?" (p.18, grifo nosso) - repetida, ao final do conto, pelo protagonista à outra mulher ressoa como um indício de desorientação. No entanto, isso se deve menos a uma dificuldade de mapear cognitivamente a cidade pós-moderna do que a uma crise de identidade resultante da percepção do sujeito de que o "lugar" na estrutura social que esperava ocupar (ou "suturar-se") não se encontra disponível. Como atesta Bauman (2004), a junção de fragmentos de valores, culturas e relações sociais em um todo coesivo e totalizante, a que damos o nome de identidade, não é mais possível (p.53).

Entretanto, a frustração dessa expectativa sofrida pelo protagonista não gera um grande abalo em seu ânimo. Mesmo em momentos de perdas subjetivas intensas, como no instante em que abandona a rede de familiaridade e penetra na terra devastada de Coalinga, o protagonista parece incapaz de esboçar sentimentos autênticos. Estes são reduzidos a simulacros de sensações como dor — "Ele quer sentir alguma coisa. Pressiona o salto de uma bota com força contra o bico da outra" (p.14) — ou arrependimento: "O cheiro forte e o calor estão fazendo seus olhos lacrimejarem. Ele esfrega a manga da camisa sobre eles e crê por um segundo que está chorando de verdade; acredita que o gesto tem a ver com algum tipo de tristeza" (p.14-15).

A perda da capacidade de expressar sentimentos ocorre de maneira crescente na medida em que o protagonista vai deixando de se constituir como um sujeito centrado ou completo. Um mês antes de deixar a esposa, ele ainda era capaz de sentir emoções como fervor e excitação (p.16), bem como medo e repugnância ao chegar a Coalinga (p.11). No entanto, conforme ele se aproxima da metrópole pós-moderna, não há quase nenhuma materialização de sentimentalidade. Durante o telefonema final, por exemplo, quando o protagonista se dá conta de que seus planos foram frustrados, tampouco há comoção por parte do protagonista. Embora se sinta obviamente confuso, ele não reage com a típica violência masculina encontrada no universo ficcional do autor. O narrador limita-se a fornecer uma imagem de queda, que sugere a decepção da personagem, ao 
comentar que este "ouve o barulho do homem gordo caindo na piscina lá fora", 5 e em lugar do extravasamento dessa emoção, há apenas silêncio e indiferença: "Então nada. Uma sirene distante" (p.18, grifo nosso).

Em parte, isso se deve ao fato de que as figuras masculinas em Shepard tendem a interpretar até as mais básicas expressões de sentimentos como vulnerabilidade e, dessa forma, seguem o "modelo tradicional de masculinidade emocionalmente reprimida" (McDONOUGH, 2002, p.157), que os toma incapazes de demonstrar emoções de modos produtivos.

Contudo, parece mais acertado ler essa perda da afetividade em geral como mais um efeito da fragmentação do sujeito. Com o colapso da identidade calcada no sujeito centrado, conforme observa Jameson (2006), a materialização dos afetos e emoções é dificultada em razão de que o "próprio problema da expressão está intimamente ligado a uma concepção do sujeito como receptor monádico, cujos sentimentos são expressos através de uma projeção no exterior" (p.42). O relativo apagamento das distinções claras entre o fora - representados pelo próprio corpo, pela sociedade, pelo Outro - e o dentro (a crença na existência de um centro nocional, um ego ou um "eu" consciente e intacto) compromete a externalização desses sentimentos. Isso não equivale a dizer que todo afeto foi apagado da cultura pós-moderna, mas que a materialização dessas emoções, de acordo com Jameson, tende a perder profundidade, passando a figurar apenas como simulacros de imagens superficiais e desistoricizadas (2006, p.38-43). No caso de "Coalinga 1/2 Way", esse dado se reverte não apenas nos traços da metrópole pós-moderna já elencados, mas também na própria construção da narrativa, que é permeada por uma prosa descomplicada, que lembra a impassibilidade minimalista, repleta de sentenças paratáticas sem ligações interoracionais rigorosas.

O conto não oferece resoluções para o impasse vivenciado pelo protagonista, nem tampouco poderíamos esperar algum tipo de "fechamento" de um texto que, como buscamos salientar, toca em pontos sensíveis da identidade humana. James (2002) observa que em Great Dream of Heaven "não há grandes resoluções, apenas pequenos acontecimentos dotados de condensação poética" (p.30). Contudo, a julgar pelo histórico de personagens semelhantes criados por Shepard, é de se supor que o

\footnotetext{
${ }^{5}$ Cabe notar que o autor já havia associado decepções por conta de crises entre casais à imagem da queda do corpo humano na água: "No apartamento vizinho, um casal discute / Ele fica dizendo: 'Não, Lorraina, não faça isso!' / Ela fica dizendo: 'Por quê?' / Nadadores caem na piscina lá fora” (SHEPARD, 1982, p. 108).
} 
protagonista de "Coalinga 1/2 Way", como uma infinidade de outros patriarcas desajustados que tumultuam suas obras, provavelmente acabaria seus dias buscando isolamento no deserto mais próximo.

\section{Considerações finais}

Com Véras (2004) compartilhamos da noção de que "a cidade é um símbolo complexo, que exprime a tensão entre a racionalidade geométrica e o emaranhado da existência humana" (p.119). Com vistas a uma compreensão, ainda que contextual e provisória, dessa interação entre homem e espaço urbano, fomos buscar no domínio da arte literária formas de representação artística onde a identidade se instanciasse por meio de bases territoriais.

A ficção do escritor norte-americano Sam Shepard tem mostrado ao longo dos anos uma relação bastante produtiva no tocante à associação de sentidos poéticos a determinados ambientes rurais e urbanos da América. Como espaços emocionais, esses espaços simbólicos, que coincidem muitas vezes com lugares empíricos, emergem como cenários de formação, deformação e transformação de identidades.

Por essa razão, nosso trabalho vale-se de pressupostos teóricos, sobretudo da crítica literária e da sociologia, bem como de outros saberes, para tentar articular conceitos tão complexos e, em nosso tempo, tão fluidos como identidade e sujeito (cf. HALL, 1987, 1992; RINCÓN, 1995; BAUMAN, 2004) à leitura do objeto estético e sua vinculação com o espaço urbano. Em posse de três conceitos teóricos distintos de manifestações identitárias (os sujeitos do Iluminismo, sociológico e pós-moderno), procedemos à análise interdisciplinar das três grandes transformações de ambiente e de personalidade sofridas pelo protagonista do texto literário "Coalinga 1/2 Way", de Shepard.

Por meio dessas análises, observamos que a passagem da personagem principal por três diferentes espaços urbanos exerce impacto direto sobre sua identidade, que deixa de ser centrada e uniforme, quando este ainda está junto à sua família e comunidade, e passa por estágios de progressivo questionamento até chegar à crise total e ao descentramento, quando o protagonista atinge o final de sua jornada - a cosmópole pós-moderna por excelência, Los Angeles (cf. SOJA, 1989, 1995).

Essa progressiva fragmentação da identidade unitária em identidades múltiplas e conflitantes vivenciada pela personagem reflete-se no espaço urbano da grande metrópole californiana, que é representada, tanto em "Coalinga 1/2 Way" como em 
outras obras do autor, como um espaço de instabilidades, superficialidades e descentramentos. Após passar por perdas subjetivas complexas, o texto sugere que o protagonista provavelmente buscará refúgio no deserto Mojave por não suportar a vida em sociedade, o que é um comportamento típico dos patriarcas do universo ficcional de Shepard. O deserto, como o reverso perfeito do espaço urbano, exerce um tipo de magnetismo sobre as personagens do autor. Talvez esse fascínio tenha que ver com um certo ideal de desaparecimento, de obliteração completa do $e u$, conforme explicita Baudrillard ao referir-se ao deserto americano como uma "crítica extática da cultura, uma forma extática de desaparecimento", isto é, um negativo da superfície terrestre, uma "rede fossilizada de inteligência inumana, de radical indiferença" aonde o sujeito vai para buscar um "suicídio em câmera lenta" ou uma espécie de "morte por extenuação das formas" (1999, p.6-7).

\section{Referências bibliográficas}

ARONOWITZ, Stanley. 1995. Reflections on Identity. In: RAJCHMAN, John (Ed.) The Identity in Question. New York and London: Routledge, p.111-127.

AUSLANDER, Philip. 2004. Postmodernism and Performance. In: CONNOR, Steven (Ed.) The Cambridge Companion to Postmodernism. Cambridge: Cambridge University Press, p.97-115.

BAUDELAIRE, Charles. 2007. Pequenos poemas em prosa (O spleen de Paris). Tradução de Dorothée de Bruchard. São Paulo: Hedra.

BAUDRILlARD, Jean. 1999. America. 10th ed. Trans. Chris Turner. New York: Verso.

1993. The Evil Demon of Images and The Precession of Simulacra. In: DOCHERTY, Thomas (Ed.). Postmodernism: A Reader. New York: Columbia University Press, p.194-199.

BAUMAN, Zygmunt. 2004. Identity. Cambridge: Polity.

BYERS, Thomas B. 1995. Terminating the Postmodern: Masculinity and Pomophobia. Modern Fiction Studies, v. 41, n. 1, p.5-33, Spr.

CLUM, John M. 2002. The Classic Western and Sam Shepard's Family Sagas. In: ROUDANÉ, Matthew (Ed.). The Cambridge Companion to Sam Shepard. Cambridge: Cambridge University Press, p.171-188.

COHN, Ruby. 1988. Twentieth-Century Drama. In: ELLIOTT, Emory (Ed.). Columbia Literary History of the United States. New York: Columbia University Press, p. 11011125. 
DAVIS, Mike. 1992. City of Quartz: Excavating the Future in Los Angeles. New York: Vintage.

DEMASTES, William W. 1987. Understanding Sam Shepard's Realism. Comparative Drama, v. 21, n. 3, p.229-248, Fall.

DEROSE, David J. 1992. Sam Shepard. New York: Twayne.

DOCHERTY, Thomas (Ed.). 1993. Postmodernism: A Reader. New York: Columbia University Press.

ELIOT, T. S. 2004. A terra desolada / The Waste Land. In: Obra completa, v.I. Tradução de Ivan Junqueira. São Paulo: Arx, p.137-173.

GÖRMEZ, Aydin. 2007. Man, Woman, Violence and Sam Shepard. Tiyatro Araştırmaları Dergisi, v.24. Ankara, Türkiye, p.125-143.

GRAY, Richard. 2001. A Brief History of American Literature. Oxford: WileyBlackwell.

GREGSON, Ian. 2004. Postmodern Literature. London: Arnold/Oxford.

HALL, Ann C. Sam Shepard's Nondramatic Works. 2002. In: ROUDANÉ, Matthew (Ed.). The Cambridge Companion to Sam Shepard. Cambridge: Cambridge University Press, p.247-256.

HALL, Stuart. 1992. The Question of Cultural Identity. In: HALL, Stuart; HELD, David; McGREW, Tony (Eds.). Modernity and its Futures. Cambridge: Polity, p.273316.

Minimal Selves. 1987. In: APPIGNANESI, Lisa (Ed.). The Real Me: Postmodernism and the Question of Identity. ICA Documents 6. London: The Institute of Contemporary Arts, p.44-46.

JAMES, Caryn. 2002. Cast Adrift. Rev. Great Dream of Heaven by Sam Shepard. The New York Times Book Review. New York, 03 Nov 2002. Section 7, Column 3, p.30.

JAMESON, Fredric. 2006. Pós-modernismo: a lógica cultural do capitalismo tardio. 2.ed. Tradução de Maria Elisa Cevasco. São Paulo: Ática.

1986. Third-World Literature in the Era of Multinational Capitalism. Social Text, v.1, n.15, p.65-88.

KING, Kimball. Introduction. 1988. In: (Ed.). Sam Shepard: A Casebook. New York and London: Garland, p.ix-xviii.

LOCKE, John. 1953. An Essay Concerning Human Understanding. Vol 1. New York: Dover Publications.

LYOTARD, Jean-François. 1993. Answering the Question: What Is Postmodernism? In: DOCHERTY, Thomas (Ed.). Postmodernism: A Reader. New York: Columbia University Press, 1993, p.38-46.

1988 [1979]. O pós-moderno. Tradução de Ricardo Corrêa Barbosa. 3.ed. Rio de Janeiro: José Olympio. 
McDONOUGH, Carla J. 2002. Patriarchal Pathology from The Holy Ghostly to Silent Tongue. In: ROUDANÉ, Matthew (Ed). The Cambridge Companion to Sam Shepard. Cambridge: Cambridge University Press, p.154-170.

McGHEE, Jim. 1993. True Lies: The Architecture of the Fantastic in the Plays of Sam Shepard. New York: Peter Lang.

MURPHY, Brenda. 2002. Shepard Writes About Writing. In: ROUDANÉ, Matthew (Ed.). The Cambridge Companion to Sam Shepard. Cambridge: Cambridge University Press, p. 123-138.

RINCÓN, Carlos. 1995. La no simultaneidad de lo simultaneo: Postmodernidad, globalización y culturas en América Latina. 2.ed. Bogotá: Universidad Nacional.

ROUDANÉ, Matthew. 2002. The Cambridge Companion to Sam Shepard. Cambridge: Cambridge University Press.

SANTOS, Boaventura de Souza. 2000. Pela mão de Alice: o social e o político na pósmodernidade. 7. ed. São Paulo: Cortez.

SHAKESPEARE, William. 2006. The Complete Works of William Shakespeare. London: Geddes \& Grosset.

SHEPARD, Sam. 2006. Fool For Love and Other Plays. New York: Dial Press. 2005. Seven Plays. New York: Dial Press. . 2003. Grande sonho do céu. Tradução de Sérgio Viotti. São Paulo: Arx. 2002. Great Dream of Heaven. New York: Knopf. 1996. Simpatico. New York: Vintage.

1982. Motel Chronicles. With Photographs by Johnny Dark. San Francisco: City Lights, 1982.

SHEWEY, Don. 1997. Sam Shepard. Updated Edition. New York: Da Capo Press.

SIEGEL, Mark. 1982. Holy Ghosts: The Mythic Cowboy in the Plays of Sam Shepard. Rocky Mountain Review of Language and Literature, v. 36, n. 4, p.235-246.

SILVA, Tomás Tadeu da. 2005 [2000]. A produção social da identidade e da diferença. In: _. (Org.). Identidade e diferença: A perspectiva dos Estudos Culturais. 4.ed. Petrópolis, RJ: Vozes, p.73-102.

SMITH, Philip. 2001. Cultural Theory: An Introduction. Oxford: Blackwell.

SOJA, Edward W. 1995. Postmodern Urbanization: the Six Restructurings of Los Angeles. In: WATSON, Sophie; GIBSON, Katherine (Eds.). Postmodern Cities and Spaces. Oxford: Blackwell, p.125-137.

1989. Taking Los Angeles Apart. In: Postmodern Geographies: The Reassertion of Space in Critical Social Theory. London: Verso, p.222-248. 
TRODD, Colin. 2001. Postmodernism and Art. In: SIM, Stuart (Ed.). The Routledge Companion to Postmodernism. London and New York: Routledge, p.89-100.

VATTIMO, Gianni. 2007. O fim da modernidade: niilismo e hermenêutica na cultura pós-moderna. Tradução de Eduardo Brandão. 2.ed. São Paulo: Martins Fontes.

VÉRAS, Maura Pardini Bicudo. 2004. DiverCidade. São Paulo: Educ.

WETZSTEON, Ross. 2006. Introduction. In: SHEPARD, Sam. Fool For Love and Other Plays. New York: Dial Press, p. 1-15.

WIDMER, Markus. 1998. Los Angeles as Postmodern Space. Munich: Grin.

WOODWARD, Kathryn. 2005 [2000]. Identidade e diferença: uma introdução teórica e conceitual. In: SILVA, Tomaz Tadeu da Silva (Org. e Trad.) Identidade e diferença: A perspectiva dos Estudos Culturais. 4.ed. Petrópolis, RJ: Vozes, p.7-72.

ZELLAR, Brad. Short Stories by Playwright Shepard Mostly Shine. Rev. Great Dream of Heaven by Sam Shepard. Minneapolis Star Tribune, Minneapolis, MN, 20 Oct 2002, p.20. 
Para citar essa obra:

SOBREIRA, Ricardo. Espaços urbanos como arena de (trans)formações identitárias na literatura contemporâneas. In: RUA [online]. 2014, nº. 20. Volume 1 - ISSN 1413-2109. Consultada no Portal Labeurb - Revista do Laboratório de Estudos Urbanos do Núcleo de Desenvolvimento da Criatividade www.labeurb.unicamp.br/rua/

Capa: MILLER, Richard. 1950. James Dean, car lighter. Disponível em: http://www.sfae.com/index.php?pg=302390

Laboratório de Estudos Urbanos - LABEURB

Núcleo de Desenvolvimento da Criatividade - NUDECRI

Universidade Estadual de Campinas - UNICAMP

http://www.labeurb.unicamp.br/

Endereço:

LABEURB - LABORATÓRIO DE ESTUDOS URBANOS

UNICAMP/COCEN / NUDECRI

CAIXA POSTAL 6166

Campinas/SP - Brasil

CEP 13083-892

Fone/ Fax: (19) 3521-7900

Contato: http://www.labeurb.unicamp.br/contato 